\title{
Cryptic diversity and gene introgression of Moinidae (Crustacea: Cladocera) in Nigeria
}

Zhixiong Deng | ORCID: 0000-0002-9221-9231

MOE Key Laboratory for Biodiversity Science and Ecological Engineering, School of Life

Science, Fudan University, Songhu Road 2005, Shanghai, China

\section{Yijun $\mathrm{Ni}$}

MOE Key Laboratory for Biodiversity Science and Ecological Engineering, School of Life Science, Fudan University, Songhu Road 2005, Shanghai, China

\section{Jinhui Wang}

MOE Key Laboratory for Biodiversity Science and Ecological Engineering, School of Life Science, Fudan University, Songhu Road 2005, Shanghai, China

\section{Chike Chukwuenyem Ebido | ORCID: 0000-0002-0493-4906}

MOE Key Laboratory for Biodiversity Science and Ecological Engineering, School of Life Science, Fudan University, Songhu Road 2005, Shanghai, China

Department of Zoology and Environmental Biology, University of Nigeria, 4100o1, Nsukka, Enugu State, Nigeria

\section{Elijah Chibueze Odii}

Department of Zoology and Environmental Biology, University of Nigeria, 4100o1, Nsukka, Enugu State, Nigeria

\section{Joseph Onyekwere Okoro}

Department of Zoology and Environmental Biology, University of Nigeria, 4100o1, Nsukka, Enugu State, Nigeria

\section{David Blair}

College of Marine and Environmental Sciences, James Cook University, Townsville, Qld 4811, Australia

\section{Wei $\mathrm{Hu}$}

MOE Key Laboratory for Biodiversity Science and Ecological Engineering, School of Life Science, Fudan University, Songhu Road 2005, Shanghai, China 


\author{
Mingbo Yin \\ MOE Key Laboratory for Biodiversity Science and Ecological Engineering, School of Life \\ Science, Fudan University, Songhu Road 2005, Shanghai, China \\ yinm@fudan.edu.cn
}

\begin{abstract}
The distribution and species/lineage diversity of freshwater invertebrate zooplankton is understudied in Sub-Saharan Africa. In the present study, we explored the lineage diversity and regional distribution of Moinidae (Crustacea: Cladocera) species in Southeast Nigeria. Three species of Moinidae were identified, based on morphology, in 11 of 32 Nigerian lakes examined. Their phylogenetic relationships were investigated based on mitochondrial DNA sequences (cytochrome oxidase $c$ subunit I gene; COI) and two nuclear internal transcribed spacer regions (ITS-1 and ITS-2). Three cor lineages were detected, corresponding to the morphological species. Two of the cor lineages are newly reported, but one COI lineage (and the haplotype found) is globally distributed, suggesting an ability of moinids to disperse over long distances. Interestingly, two individuals that were morphologically $M$. cf. macrocopa and had ITs alleles typical of that species had mtDNA sequences typical of $M$. cf. micrura. Additionally, one individual that corresponded morphologically to $M$. cf. macrocopa (and also had a mitochondrial sequence typical of $M$. cf. micrura) had one ITs-2 allele typical of that species and one typical of $M$. cf. micrura. This discordance between mtDNA and nuclear phylogenies suggests gene introgression and/or hybridization between different species within the genus. Our data shows the lineage distribution/diversity and the presence of gene introgression/interspecific hybridization among moinid species from a tropical region.
\end{abstract}

\title{
Keywords
}

new lineages - gene introgression - Moinidae - Nigeria

\section{Introduction}

"Cosmopolitanism", based on the apparent lack of morphological variation among presumed conspecific populations across wide regions, was widely accepted in the past (BaasBecking, 1934). This was especially so for freshwater invertebrate zooplankton, as they have large population sizes and strong dispersal abilities (Bohonak \& Jenkins, 2003). However, some "species" that have been claimed to be cosmopolitan are inreasingly shown to be groups or complexes of morphologically similar species (Frey, 1987). More recently, extensive genetic studies have confirmed that many widespread freshwater invertebrate "species" (based on morphological criteria) often consist of very distinct, locally endemic lineages, some of which likely represent cryptic species (Marrone et al., 2013; Neretina et al., 2021; Penton et al., 2004).

Gene introgression/hybridization is frequently observed in nature, with at least $25 \%$ of plant species and 10\% of animal species engaging in interspecific crosses (Mallet, 2005). This phenomenon can be inferred from mito-nuclear incongruence among phylogenetic trees (Linder \& Rieseberg, 2004), 
which is the frequently observed across taxa (e.g., Degnan \& Rosenberg, 2006; Nichols, 2001; Rosenberg, 2013; Thielsch et al., 2017). Successful interspecific hybridization has been often documented in cyclical parthenogens, such as aphids (Delmotte et al., 2003) and zooplanktonic cladocerans (Hebert, 1985; Ma et al., 2019; Xu et al., 2013).

The Moinidae (Crustacea: Cladocera) is a speciose cladoceran family belonging to the order Anomopoda, close relatives of the Daphniidae. Based on the checklist from the FADA website (Kotov et al., 2013), this family includes 35 valid species in two valid genera: Moina Baird, 1850 (34 species) and Moinodaphnia Herrick, 1887 (1 species). Moinidae occur in a wide range of waterbodies, but are frequently present in temporary waters (Smirnov, 1976). Similar to other zooplankton (e.g., Daphnia Mueller, 1776), Moinidae utilize cyclical parthenogenesis, in which several generations of parthenogenetically produced females alternate with a sexual generation with males producing sperm and females producing haploid eggs (Dumont \& Negrea, 2002). When the environmental conditions are suitable, parthenogenesis is common resulting in rapid population growth. When unfavorable conditions arise, such as food shortage or overcrowding, moinid individuals can switch to sexual production of males and sexual haploid eggs that require fertilization, followed by diapause. This sexual phase can lead to interspecific hybridization if closely related species co-occur (Hebert, 1985). Indeed, a very recent study showed discordances between mitochondrial DNA (mtDNA) and nuclear ITs-1 phylogenies of the genus Moina in China, which is indicative of interspecific introgression and hybridization (Ni et al., 2019).

Until now, Moinidae has received little attention with respect to molecular systematics (e.g., Bekker et al., 2016; Mirabdullayev,
1998; Neretina \& Kirdyasheva, 2019; Ni et al., 2019; Padhye \& Dumont, 2014). The first genetic study discovered that $M$. cf. micrura Kurz, 1875 from Europe and Australia belonged to two genetically divergent but morphologically similar species (Petrusek et al., 2004). Later studies using DNA-barcoding detected a cryptic species of the M. brachiata Jurine, 1820 complex in Hungary (Nedli et al., 2014) and in Northern Eurasia (Bekker et al., 2016). More recently, analysis of COI sequences revealed four species complexes with eleven lineages of Moina across China (Ni et al., 2019). Very recent integrative taxonomic studies have also explored underestimated species diversity of Japanese moinids (Makino et al., 2020), diversity in the $M$. macrocopa complex worldwide (MontoliuElena et al., 2019) and in the M. micrura complex worldwide (Elias-Gutierrez et al., 2019). There have been relatively few studies including moinids from Africa (Etile et al., 2020; Ghaouaci et al., 2018; Jeje, 1989; Marrone et al., 2016; Smirnov, 2008). Based on morphology, a previous study reported $M$. reticulata Daday, 1905 in West Africa (Lamoot \& Dumont, 1974). In Nigeria, three species of Moina ( $M$. micrura, M. reticulata and $M$. dubia Richard, 1874) and one species of Moinodaphnia (Moinodaphnia macleayi King, 1853) were recorded (Jeje, 1989). However, there have been no studies on phylogeography and lineage/genetic diversity of Moinidae from Nigeria, despite the importance of this region as a biogeographic hotspot (e.g., Myers et al., 200o; Penner et al., 2013).

The present study assessed genetic diversity of Moinidae within a small area of Southeast Nigeria, with emphasis on possible hybridization/gene introgression. DNA sequences from three regions of the genome were used: the mitochondrial cytochrome oxidase $c$ subunit I gene (COI), and the nuclear internal transcribed spacer regions (ITS-1 and ITS-2). 
We placed Moinidae species from Southeast Nigeria in a global context by utilizing previously published sequences. We also estimated the existence and number of new lineages within the family Moinidae, by using two different species-delimitation methods. Finally, we tested the hypothesis that hybridization and introgression could occur among members of the Moinidae from tropical regions, as observed in other zooplankton elsewhere (Hebert, 1985).

\section{Methods}

\section{Sampling}

Zooplankton samples were collected from 32 locations (lakes or ponds) in Southeast Nigeria (Fig. 1) during August and September of 2018. Three or four sampling sites were selected from each location, and a plankton net (mesh size $125 \mu \mathrm{m}$ ) was hauled vertically through the water column. Samples collected from different sites in the same locations were pooled and preserved with $95 \%$ ethanol at $4^{\circ} \mathrm{C}$ in the laboratory. Moinidae was only detected in 11 out of the 32 locations investigated in this study.

\section{Morphological examination}

For morphological examination, animals were selected from alcohol-preserved samples under a dissecting microscope, placed on slides and examined under a high-resolution optical microscope (ECLIPSE Ci-S, Nikon). Ten parthenogenetic females from each species of Moinidae were examined (Supplementary Fig. S1) based on five key morphological characteristics, including head, antenna II, limb I, valve and postabdomen (Elias-Gutierrez et al., 2019; Goulden, 1968; Montoliu-Elena et al., 2019). In addition, the morphology of adult males and ephippial female (if present) from each species of Moinidae were recorded.

\section{DNA extraction and sequencing}

On average, ten individuals of Moinidae (identified based on morphological characteristics under a microscope) per location were randomly selected for DNA extraction following a standard protease-K digestion protocol (Schwenk et al., 1998). Sample sizes were low $(\mathrm{N}<3)$ for one of the 11 populations because of the low frequency of moinids in the zooplankton there. Each individual was placed in a $20 \mu \mathrm{L} \mathrm{H} 3$ buffer (10 mM Tris-HCl, pH 8.3, 0.05 $\mathrm{M} \mathrm{KCl}$, 0.005\% Tween 20 and $0.005 \% \mathrm{NP}-40$ ) with final concentration $0.1 \mathrm{mg} / \mathrm{mL}$ proteinase $\mathrm{K}$, and incubated for $16 \mathrm{~h}$ at $55^{\circ} \mathrm{C}$ in a water bath with mild shaking. The proteinase $\mathrm{K}$ was then irreversibly denatured by a 12 min incubation at $95^{\circ} \mathrm{C}$. Finally, the tube with DNA was centrifuged briefly and stored at $4^{\circ} \mathrm{C}$ before PCR.

A 68 o bp segment of the mitochondrial cytochrome $c$ oxidase subunit I (COI) gene, a 81 op segment of the first nuclearinternal transcribed spacer (ITS-1) and a 1050 bp segment of the second nuclear internal transcribed spacer (ITS-2) were used as genetic markers. For COI, PCR amplification used a standard primer pair; LCO149O and HCO2198 (Folmer et al.,1994), with cycling conditions as in our previous study ( $\mathrm{Ni}$ et al., 2019). PCR products were then purified and sequenced in the forward direction, using an ABI PRISM 373 O DNA capillary sequencer, by Majobio Bio-pharm Technology Co., Ltd (Shanghai, China). Ninety-seven individuals were successfully sequenced at the cor locus, and then an average of 10 individuals from each of the three cor lineages (corresponding to morphospecies: see below) identified (31 individuals in total; Table 1 ) were chosen for sequencing of the nuclear internal transcribed spacers (ITS-1 or/and ITS-2). Amplification of the ITS-1 and ITS-2 regions was performed using primers $18 \mathrm{SD}$ and $5.8 \mathrm{BR}, 5.8 \mathrm{BF}$ and $28 \mathrm{SD} 2 \mathrm{BR}$, respectively (Taylor et al., 2005), following the protocol used in our previous studies (Ni 


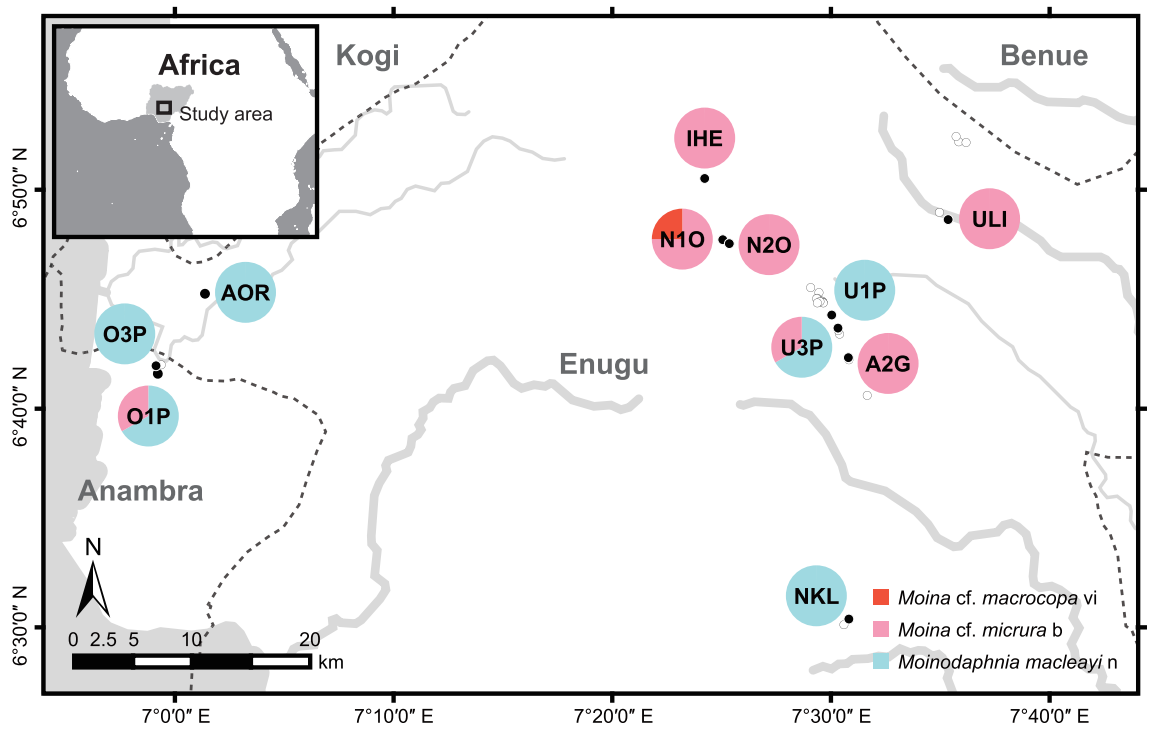

FIGURE 1 Geographic locations of sampling for Moinidae in Southeast Nigeria. Solid black circles indicate locations where moinids were present, empty circles indicate locations where no moinids were detected. Large colored circles near solid black circles represent the distribution of cor lineages. For abbreviations of location names, refer to Table 1.

et al., 2019; Wang et al., 2021). As ITs fragments sometimes had multiple heterozygous sites (because of the presence of different alleles), cloning was carried out to obtain unambiguous chromatograms (Ni et al., 2019; Wang et al., 2021). Up to 15 clones were sequenced for each ITS PCR product: only identical sequences obtained at least twice per PCR product were selected for further analysis. All ITS PCR products were sequenced using the forward primer on an ABI PRISM 3730 DNA capillary sequencer by Majobio Bio-pharm Technology Co., Ltd (Shanghai, China). All the chromatograms were carefully checked and manually corrected in MEGA X (Kumar et al., 2018), and the quality scores of the sequences were examined in Chromas Lite Version 2.1 (Technelysium Pty. Ltd., South Brisbane, Australia). For all markers, chromatograms with double peaks or noise were re-sequenced in the reverse direction, and only chromatograms with high quality sequences (Phred quality score $>40$ ) were chosen for the subsequent genetic analysis. All new sequences were submitted to GenBank and assigned accession numbers: COI: MZ505633-MZ505638, ITS-1: MZ504730-MZ504744 and ITS-2: MZ504753-MZ504780.

\section{Sequence alignment and genetic diversity}

For COI, unique haplotypes were identified in DnaSP 6 (Rozas et al., 2017). These were then aligned together with the 110 haplotypes represented among 416 reference sequences retrieved from GenBank (Supplementary Table S1), using Clustal W (Thompson et al., 1994) in MEGA X (Kumar et al., 2018). For ITs fragments, unique alleles were verified in DnaSP 6, and then aligned using MUSCLE (Edgar, 2004) in MEGA X. Twenty-five reference sequences of Moinidae ITs fragments were retrieved from GenBank (Supplementary Table S2) and aligned together with the ITS unique haplotypes in this study. For each species, the number of haplotypes $\left(\mathrm{N}_{2}\right)$, haplotype diversity $(\mathrm{H})$ and nucleotide diversity $(\pi)$ were calculated in DNASP 6 for both COI and ITs markers. Intra-individual differences 


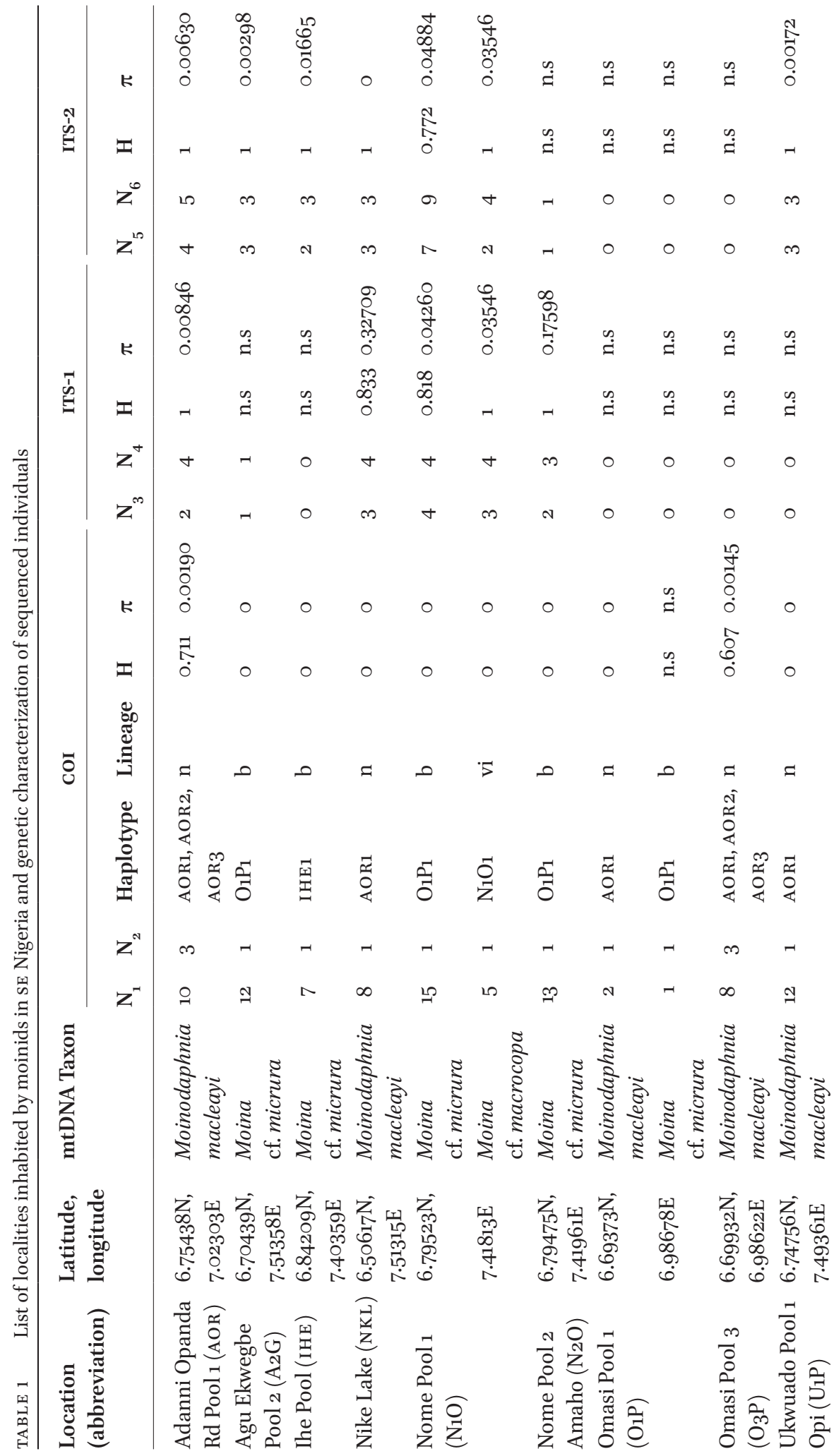




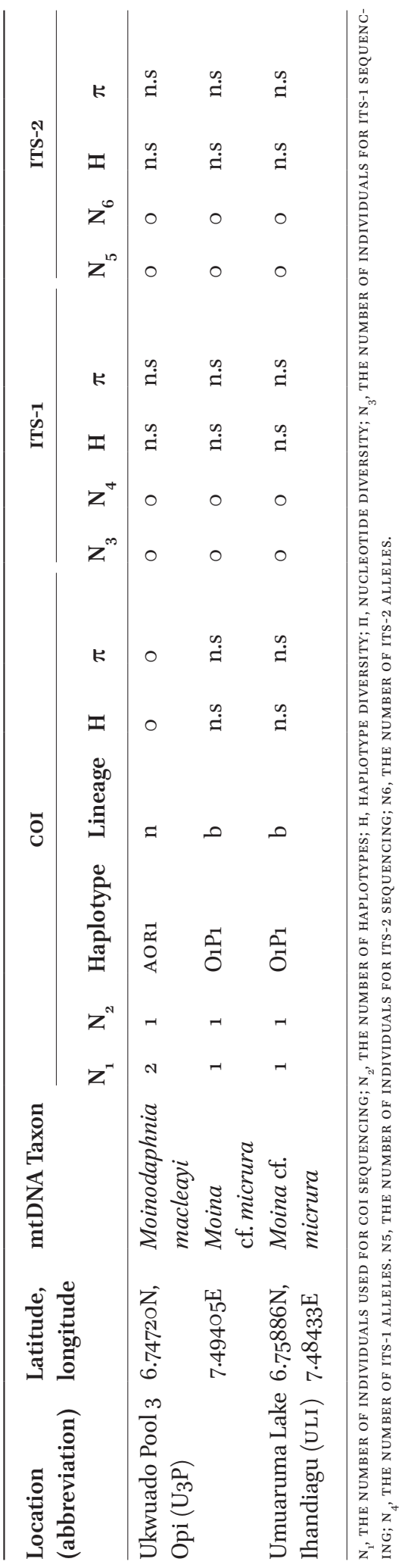

between ITS-1 or ITS-2 alleles in heterozygotes was calculated in MEGA X.

\section{Phylogenetic analyses}

Potential loss of phylogenetic signal because of substitution saturation among COI sequences was assessed using the test of Xia et al. (2003) implemented in DAMBE 5 (Xia, 2013). jModelTest 2.1.3 (Darriba et al., 2012) was then used to determine the best-fitting evolutionary models and partitioning schemes by employing the greedy algorithm and the Bayesian information criterion. A phylogenetic tree was constructed from the COI alignment applying the Bayesian method in BEAST 2 (Bouckaert et al., 2014). The analysis was run for 10,000,000 generations and a tree recorded every 1000 generations. The first $25 \%$ were discarded as burn-in, and the final 7,500 trees summarized using TreeAnnotator. GTR $+\mathrm{G}$ was found to be the best fitted substitution model (Huelsenbeck \& Ronquist, 2001). A strict clock and a birth-death tree model were used as priors to obtain an ultrametric tree for the generalized mixed Yule coalescent model analyses. Tracer vı.6 (Rambaut et al., 2018) was applied to ensure that the analysis had run for a sufficient number of generations. Ceriodaphnia Dana, 1853, a member of the Cladocera phylogenetically close to Moinidae, was used as an outgroup (Bekker et al., 2016; Ni et al., 2019). Similarly, a Bayesian phylogenetic tree was constructed separately for the ITS-1 and ITS-2 marker in BEAST 2 using the GTR $+\mathrm{I}+\mathrm{G}$ substitution model.

\section{Detection of new lineages and phylogeographic analyses}

Two independent species-delimitation methods were used to test the hypothesis that Moinidae is a complex of reproductively isolated species/lineages: the general mixed Yule coalescent model (GMYC, Pons et al., 2006) and Poisson tree processes methods 
(PTP, Zhang et al., 2013). These methods were applied to all genetic markers. The GMYC is a likelihood-based method for delimiting species/lineages by fitting within- and between-species branching models to reconstruct gene trees using an ultrametric tree. The GMYC modelling was carried out using the splits package (Ezard et al., 20o9) in R 3.6.1 (R Development Core Team, 2013). The PTP calculations were performed on the bPTP webserver (http://species.h-its.org/ptp/), with 100,000 MCMC generations, thinning set to 100 and burn-in at $25 \%$ and performing a Bayesian search. The input phylogenetic trees were generated with BEAST 2 as above. Finally, to visualize genealogical relationships among Moinidae lineages within species, COI haplotype networks were constructed in HAPLOVIEWER (Salzburger et al., 2011). Here, 626 Moinidae reference sequences, for which there was detailed collection information, were chosen from 21 geographical regions, including the Bolivia, Canada, China (Eastern Plain, Inner Mongolia-Xiangjiang Plateau, Northeast Plain, Qinghai-Tibet Plateau and Yunnan-Guizhou Plateau), Czech Republic, Hungary, India, Japan, Kazakhstan, Korea, Mexico, Russia (Central Siberian Plateau, the East European Plain, the East Siberia and the Western Siberian Plain), Spain, Thailand, and U.S.A, see Supplementary Table $S_{3}$. The maximum likelihood trees inferred with MEGA $X$ with the best model $(\mathrm{GTR}+\mathrm{G})$ were used as input.

\section{Results}

\section{Morphological examination}

Our morphological examination revealed three moinid species in Southeast Nigeria: $M$. cf. micrura, $M$. cf. macrocopa and Moinodaphnia macleayi (All the voucher specimens are preserved in Zooplankton
Collection at Fudan University; Fig. 2a-p, and Table 2). $M$. cf. micrura (Fig. 2a) and $M$. cf. macrocopa (Fig. 2h) could be distinguished by two key morphological features: arrangement of the setules on the postero-ventral margin and setae of limb I. The setules on the postero-ventral margin of $M$. cf. micrura are grouped (Fig. 2g), but those of $M$. cf. macrocopa are not. The setae of the penultimate segment of limb 1 of $M$. cf. macrocopa bears strong denticles (Fig. 2j), whereas the corresponding seta of $M$. cf. micrura bears relatively thin setules. We only found males and sexual females of $M$. cf. micrura (Fig. $2 \mathrm{~b}$ and c). The ephippium carried by the latter contains a sexual egg which is reticulated over its surface (Fig. 2c). Parthenogenetic females of $M$. macleayi could be easily distinguished from other species because they have an ocellus and a long spine on the exopod of antenna II (Fig. $2 \mathrm{~m}$ and $\mathrm{n}$ ).

\section{Genetic diversity}

A total of 97 moinid individuals (an average of 8.8 individuals per population) were successfully sequenced at the CoI ( $478 \mathrm{bp}$ in the aligned dataset); among them, six unique coI haplotypes were detected (Table 1). Three haplotypes (AOR1, AOR2 and AOR3) belonged to $M$. macleayi, two haplotypes $\left(\mathrm{O}_{1} \mathrm{P}_{1}\right.$ and IHE1) to $M$. cf. micrura and one haplotype $\left(\mathrm{N}_{1} \mathrm{O}_{1}\right)$ to $M$. cf. macrocopa (Table 1). For each morphologically defined species, the population haplotype diversity $(\mathrm{H})$ of coI ranged from $\mathrm{O}$ to 0.711 , and the population nucleotide diversity $(\pi)$ ranged from $o$ to 0.00190 (Table 1). The cor alignment (excluding the outgroup) contained 121 variable sites. In total, 15 individuals belonging to 3 species/ lineages were sequenced at locus ITS-1 ( 5 heterozygotes and 10 homozygotes, resulting in a total of 20 sequences; $677 \mathrm{bp}$ in the aligned dataset; Table 3); among them 16 unique IT S-1 alleles were detected (Tables 1 and 3). For 

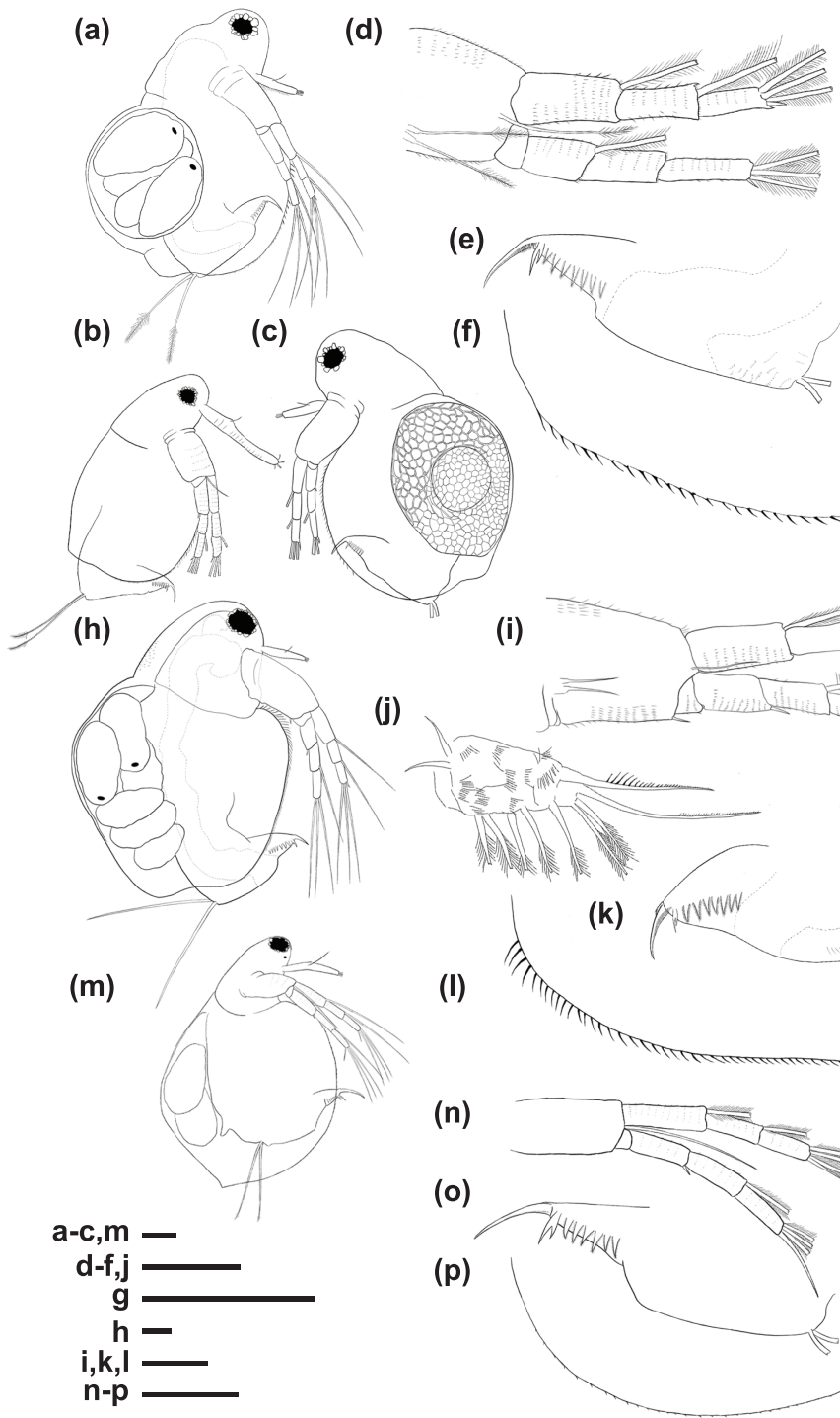

(e)

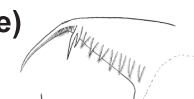

(f)

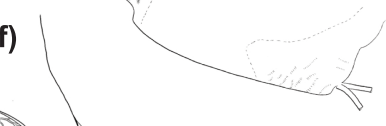

(g)

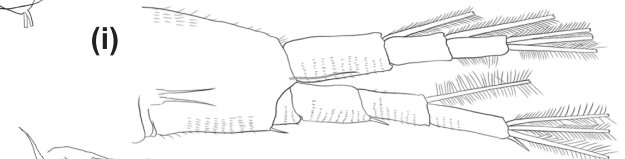

(l)

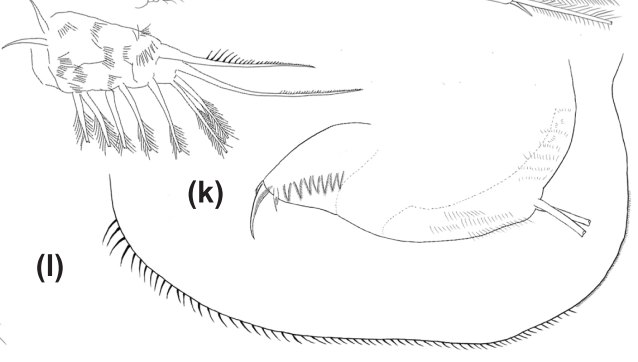

(n)

(o)

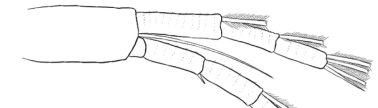

(p)

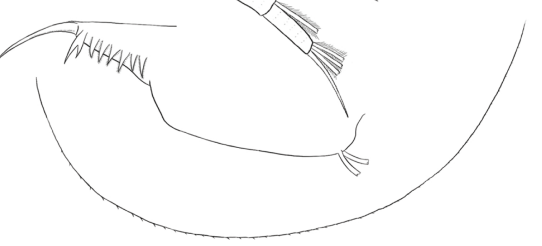

FIGURE 2 Morphology of Moinidae from Southeast Nigeria. Monia cf. micrura from the Nome Pool 2, Amaho: lateral view of (a) parthenogenetic female, (b) male and (c) ephippial female; (d) antenna II, (e) postabdomen (f) valve and (g) postero-ventral margin of valve of the parthenogenetic female. Monia cf. macrocopa, parthenogenetic female from Nome Pool 1: (h) lateral view, (i) antenna II, (j) limb I, (k) postabdomen and (l) valve. Moinodaphnia macleayi, parthenogenetic female from Adanni Opanda Rd Pool 1: (m) lateral view, (n) antenna II, (o) postabdomen and (p) valve. Scale bars $0.1 \mathrm{~mm}$. 


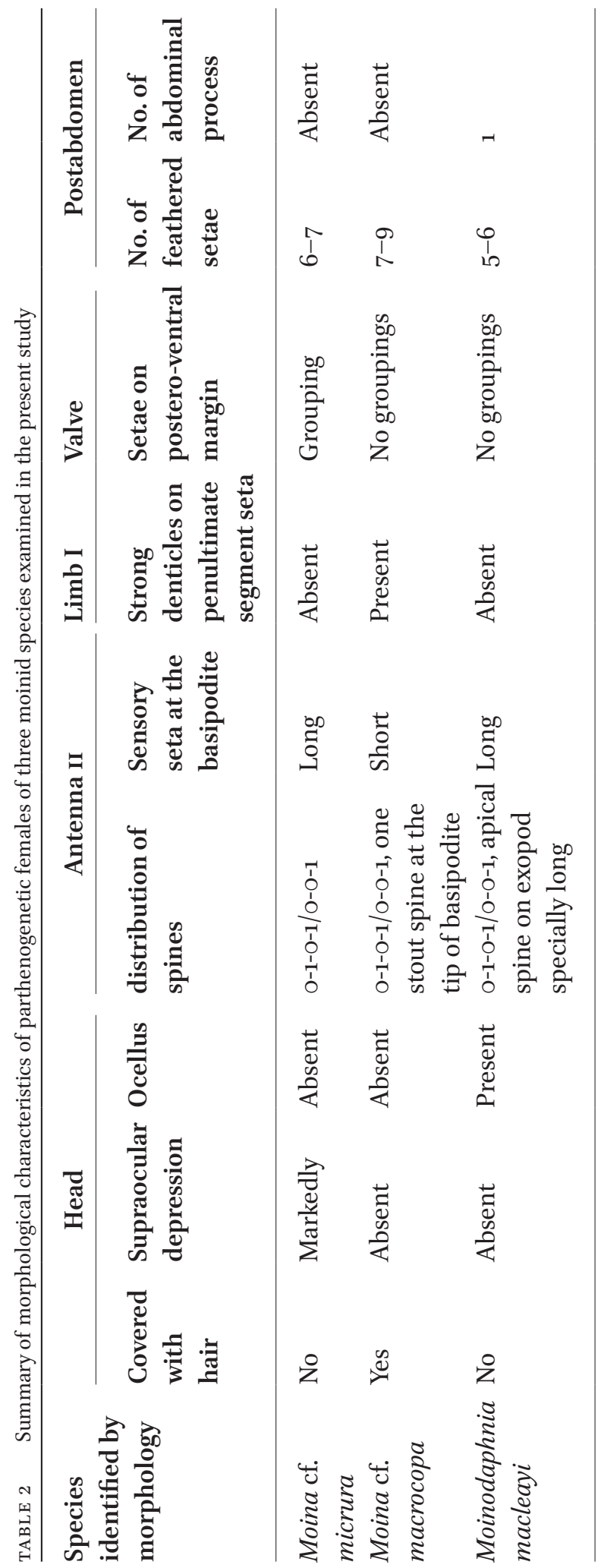




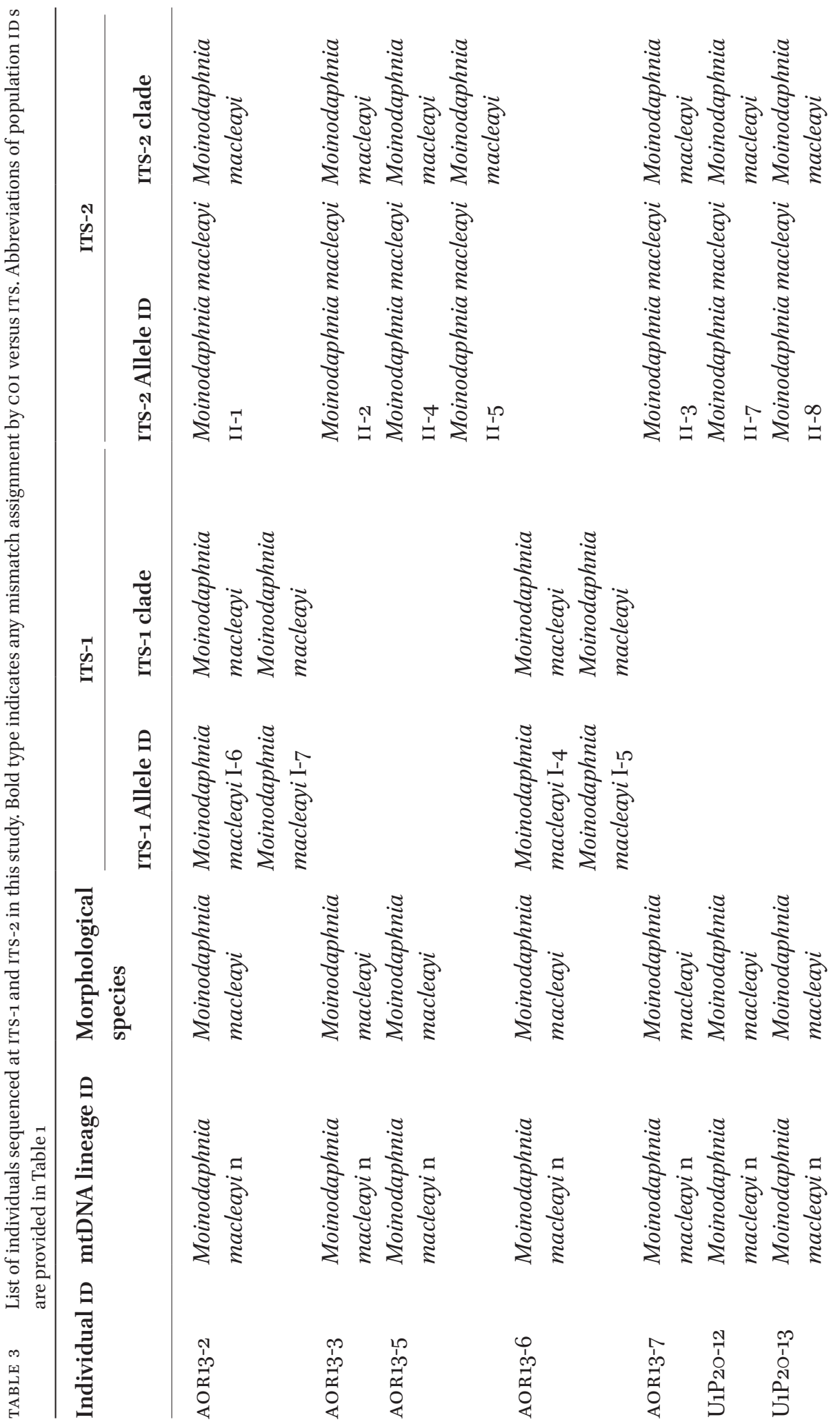




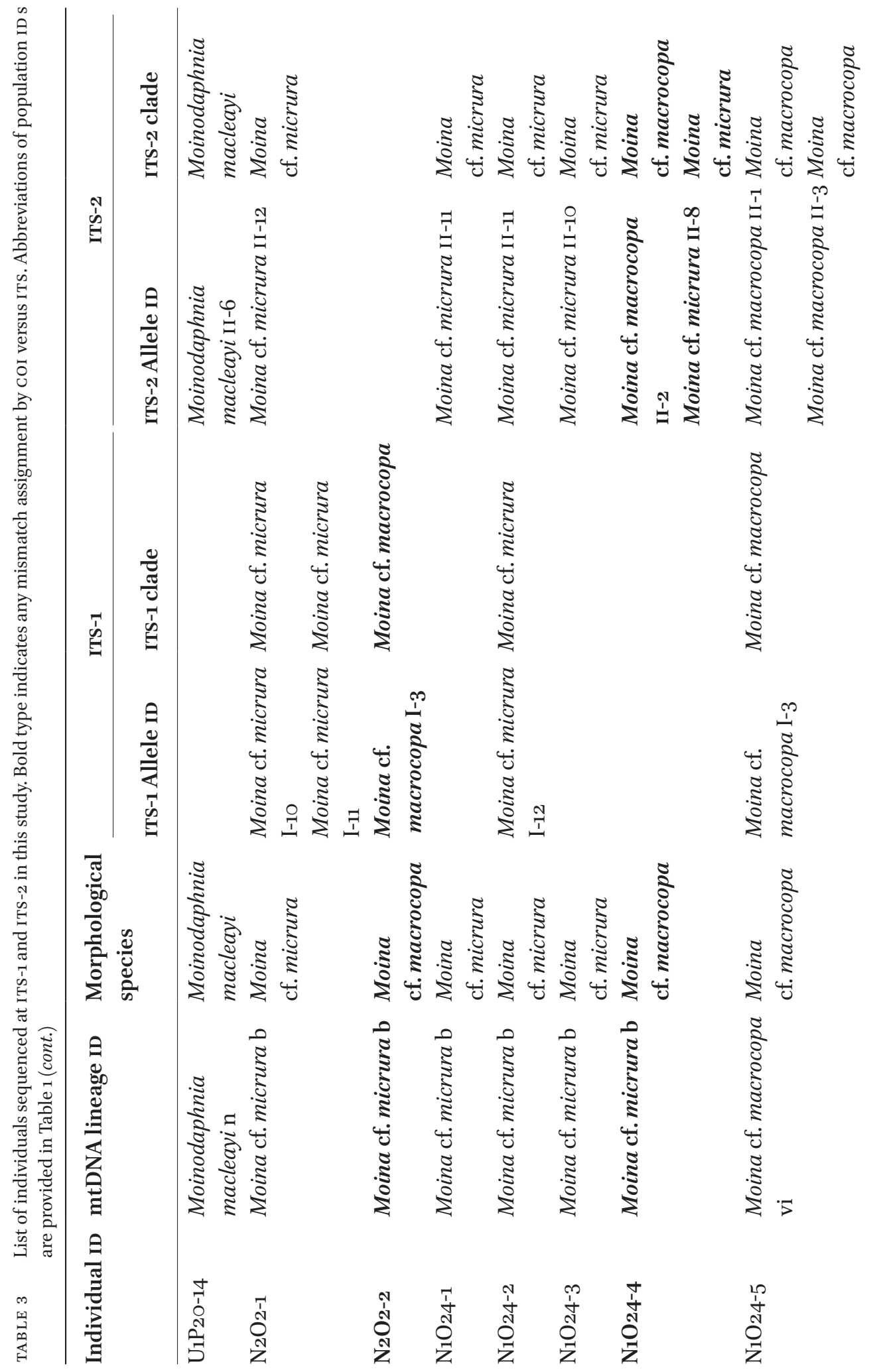




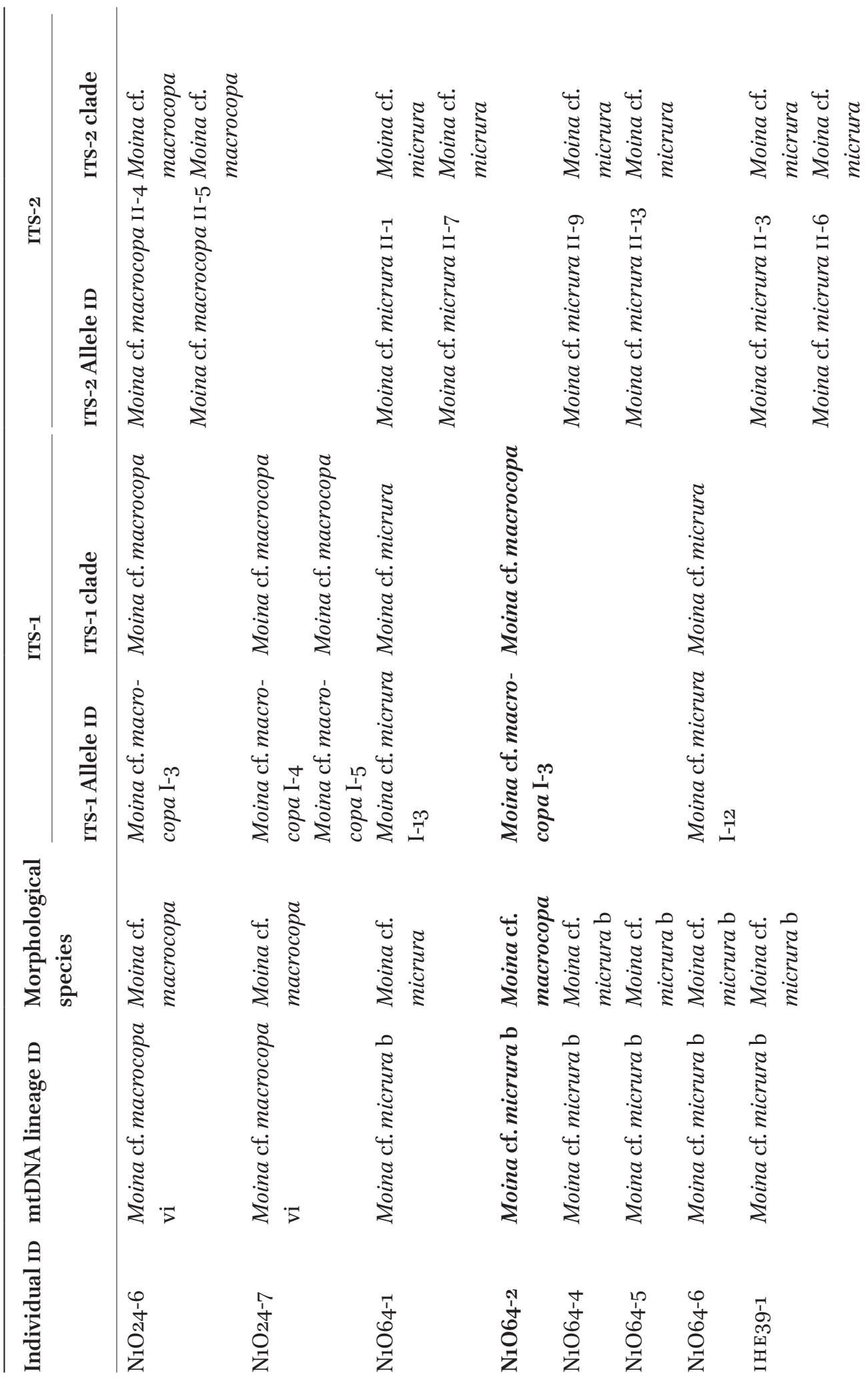




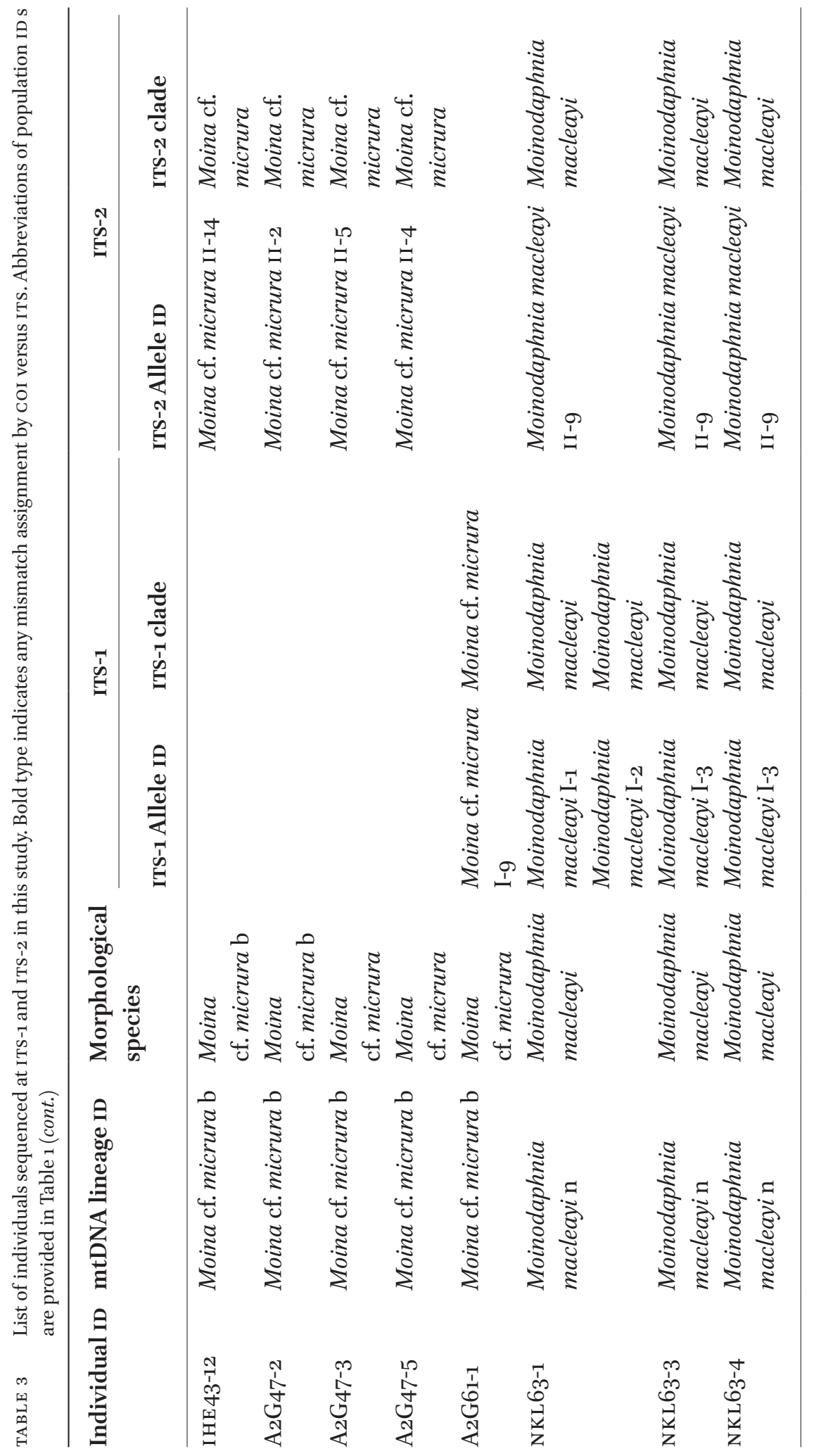


ITS-2, 26 individuals belonging to 3 species/ lineages were sequenced (6 heterozygotes and 19 homozygotes, resulting in a total of 31 sequences; 955 bp in the aligned dataset; Table $3)$; among them 28 unique ITS-2 alleles were detected (Tables 1 and 3 ). The haplotype diversity $(\mathrm{H})$ ranged from 0.818 to $1($ mean $=0.930)$ for ITS-1 and from 0.772 to $1($ mean $=0.967)$ for ITS-2, and the nucleotide diversity $(\pi)$ ranged from 0.00846 to $0.32709($ mean $=0.11792)$ and from o to 0.04884 (mean $=0.01599$ ) for ITS 2. The amount of intra-individual difference between alleles of heterozygotes at ITS-1 ranged from $1 \mathrm{bp}$ to $11 \mathrm{bp}$, and at ITS-2 ranged from 3 bp to 15 o bp (due to variable numbers of simple-sequence repeats; data not shown).

\section{Phylogeny and gene introgression}

Based on the cor Bayesian tree, two independent species-delimitation methods (i.e. GMYC and bPTP) consistently indicated that Southeast Nigerian Moinidae populations fell into three distinct lineages, each representing a single morphological species: Moina cf. macrocopa (lineage vi in Fig. 3), $M$. cf. micrura (b) and Moinodaphnia macleayi (n). Posterior probability (PP) support for these species/lineages by the bPTP method was consistently > o.9o. Our COI phylogeny shows that $M$. cf. micrura and $M$. cf. macrocopa are paraphyletic groups. One lineage of $M$. cf. micrura (lineage I) is more closely related to the $M$. cf. macrocopa clade than to the remaining $M$. cf. micrura lineages (Fig. 3). This lineage also included sequences from specimens identified as M. weismanni Ishikawa, 1896. The identity of these merits further investigation. No Nigerian sequences occupied paraphyletic positions. Both of the nuclear (i.e., ITS-1 and ITS-2) Bayesian trees also indicated the presence of three species from Southeast Nigeria (Fig. 4). Interestingly, two individuals that were morphologically $M$. cf. macrocopa and had ITs alleles typical of that species had
mtDNA sequences typical of $M$. cf. micrura (Table 3 and Fig. 4a). Additionally, one individual that corresponded morphologically to $M$. cf. macrocopa had one ITS-2 allele typical of that species and one typical of $M$. cf. micrura (Table 3 and Fig. 4b). This individual also had a mitochondrial sequence typical of $M$. cf. micrura (Table 3). Moreover, one ITs-1 allele of $M$. cf. macrocopa was shared between Chinese and Nigerian individuals. Different moinid species/lineages co-existed in the same lake across a small geographical scale in Southeast Nigeria (Table 1 and Fig. 1). Of particular note, $M$. cf. micrura and $M$. cf. macrocopa coexisted in $\mathrm{N}_{1} \mathrm{O}$ (Table 1 and Fig. 1). Intriguingly, the two introgressed individuals co-existed with both their parental species in $\mathrm{N} 1 \mathrm{O}$.

\section{Biogeography}

The name $M$. cf. micrura has been applied to moinids from more countries than any other. It has been reported from 14 out of 22 surveyed regions, including China (Eastern Plain, Inner Mongolia-Xinjiang Plateau, Northeast Plain and Yunnan-Guizhou Plateau), Czech Republic, Hungary, India, Japan, Kazakhstan, Korea, Mexico, Nigeria, Russia (East European Plain) and Spain (Fig. 5). Moinids that we classed as $M$. cf. micrura were also the most widely distributed species in Southeast Nigeria, where it was found in 7 out of 11 lakes (Fig. 1). The lineage (b) of this species in Southeast Nigeria has been found nowhere else in the world (Figs 3 and 5). The second most frequently occurring species in this study was Moinodaphnia macleayi, detected in 6 out of 11 lakes (Fig. 1). Again, the Nigerian lineage $(\mathrm{n})$ is new and known from nowhere else (Figs 3 and 5 ). One $M$. cf. macrocopa lineage (vi) was detected in a single lake $(\mathrm{NiO})$ in this study. The single Nigerian haplotype from this lineage is also known from China (Eastern 


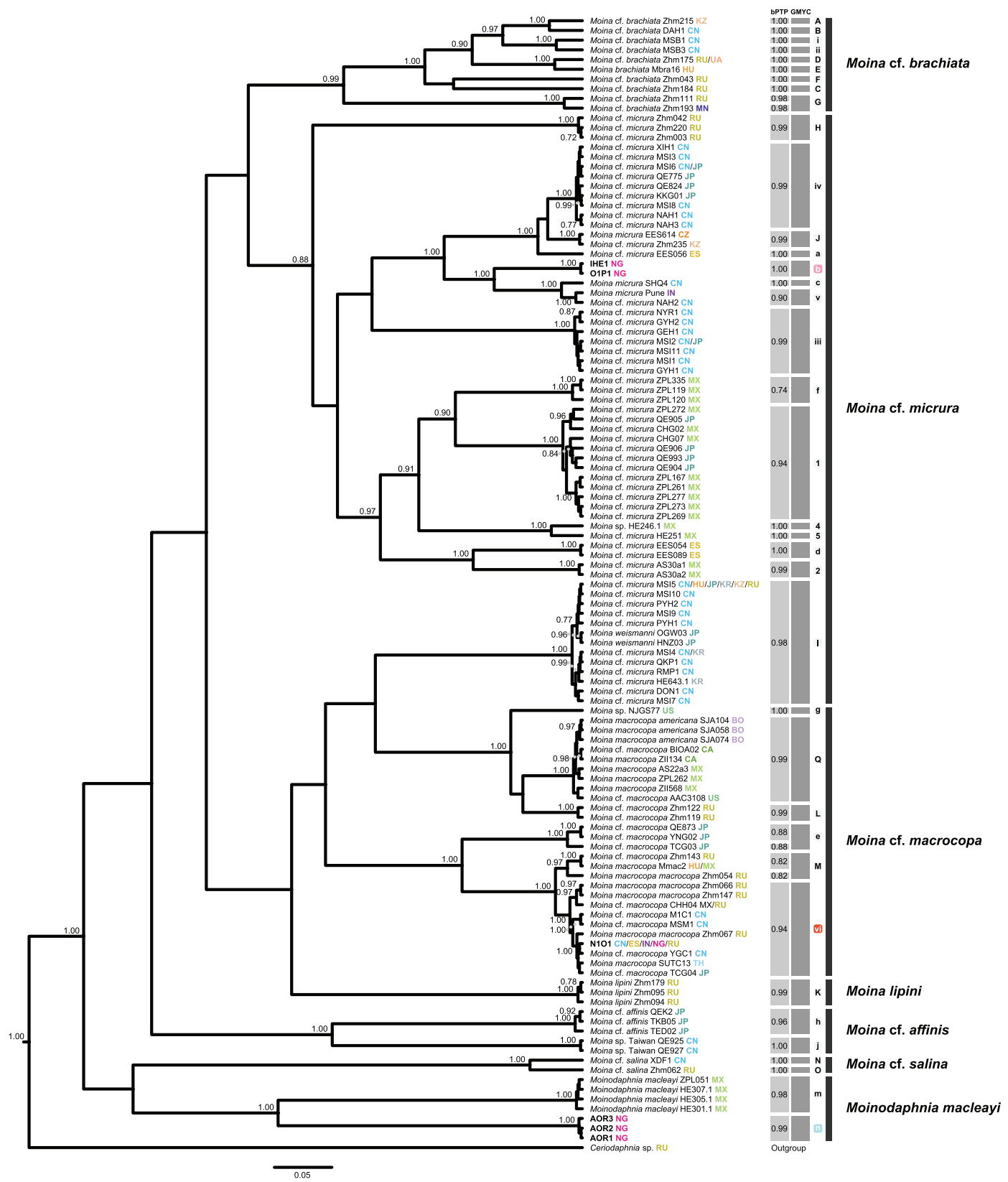

FIGURE 3 Bayesian phylogenetic tree and species- delimitation of Moinidae from Southeast Nigeria, based on the mitochondrial cor gene ( $478 \mathrm{bp}$ ). A single representative of each haplotype (for reference sequences see Supplementary Table $\mathrm{S} 1$ ) is included in the tree. Codes of Moinidae haplotypes from Nigeria are provided in Table 1. Only posterior probabilities $>0.70$ are shown. The numbers in the bands relating to the bPTP method indicate the statistical support (PP) for lineage membership. The lineage ID s are shown in columns relating to the species-delimitation methods, and the newly detected lineages from Nigeria are indicated in colored squares. Abbreviations of country names in which each haplotype was detected are, Bo: Bolivia, CA: Canada, CN: China, CZ: Czech Republic, HU: Hungary, IN: India, JP: Japan, KZ: Kazakhstan, KR: Korea, MX: Mexico, MN: Mongolia, NG: Nigeria, RU: Russia, TH: Thailand, UA: Ukraine, US: U.S.A. 

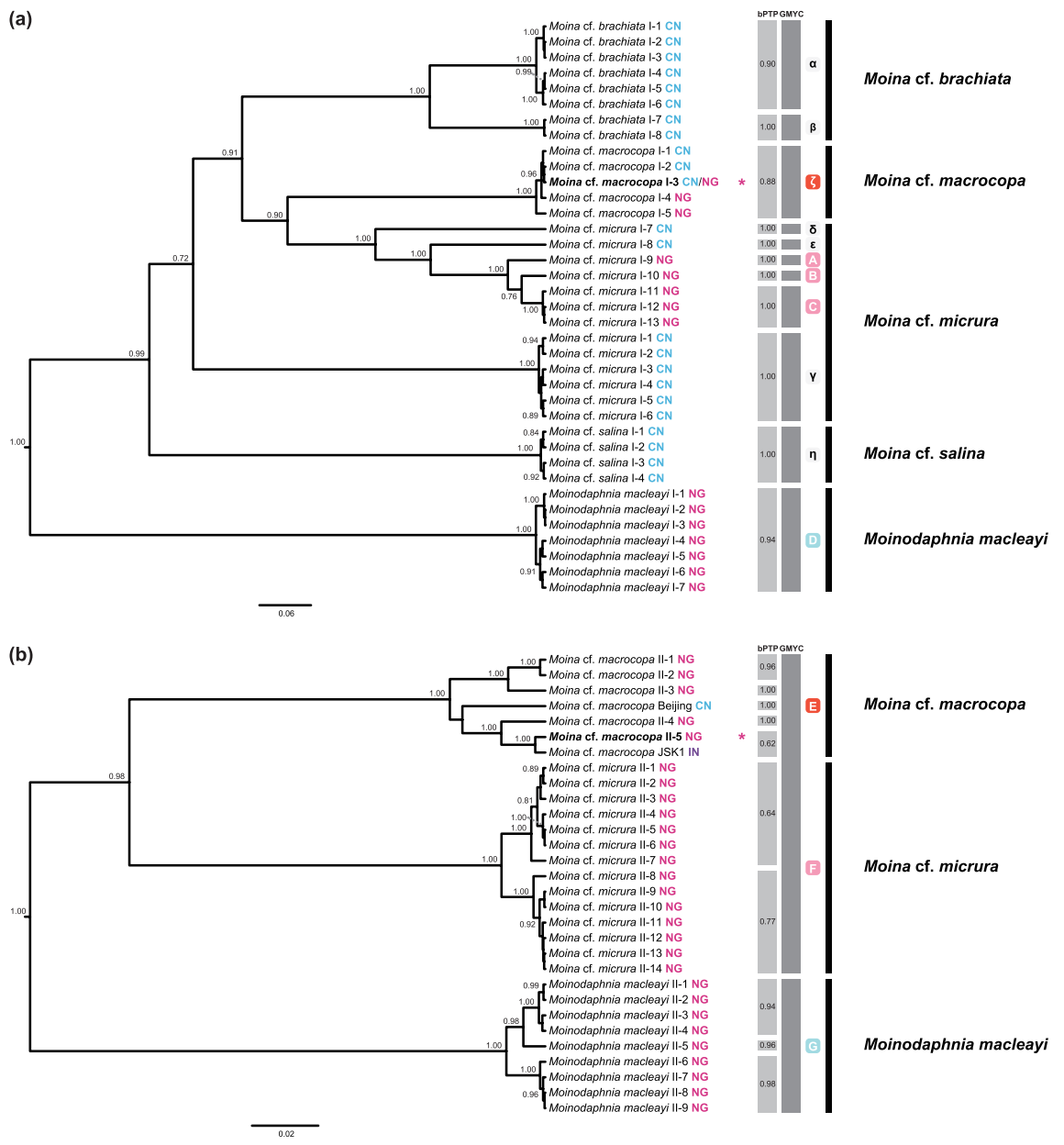

FIGURE 4 Bayesian phylogenetic tree of the (a) ITS-1 region (677 bp) and (b) ITS-2 region (955 bp) of Moinidae lineages from Nigeria. Only posterior probabilities $>0.70$ are shown. The lineage ID s are shown in columns relating to the species-delimitation methods, and those newly detected from Nigeria are indicated in colored squares. The mismatch assignments by COI and ITS-1 are in bold and highlighted with an asterisk. For abbreviations of country names refer to Fig. 3 .

Plain), India, Japan, Russia (East Siberia and Western Siberian Plain) and Spain (Fig. 5).

\section{Discussion}

\section{Lineage diversity in Moinidae from Southeast Nigeria}

In line with previous surveys from Nigeria (Egborge et al., 1994; Jeje, 1989; Ovie \& Adeniji, 1994), our morphological examination of moinids from a small geographical area in
Southeast Nigeria revealed the presence of Moina cf. macrocopa, M. cf. micrura and Moinodaphnia macleayi. Our mtDNA-based phylogeny placed each of these three species in a single lineage, nested among conspecifics from other parts of the world. Two out of these three lineages are newly reported. With the advance of genetic tools, multiple new lineages in freshwater zooplankton taxa are indeed increasingly being recognized. Examples are common among monogont rotifers (e.g., Fontaneto et al., 20o9; 


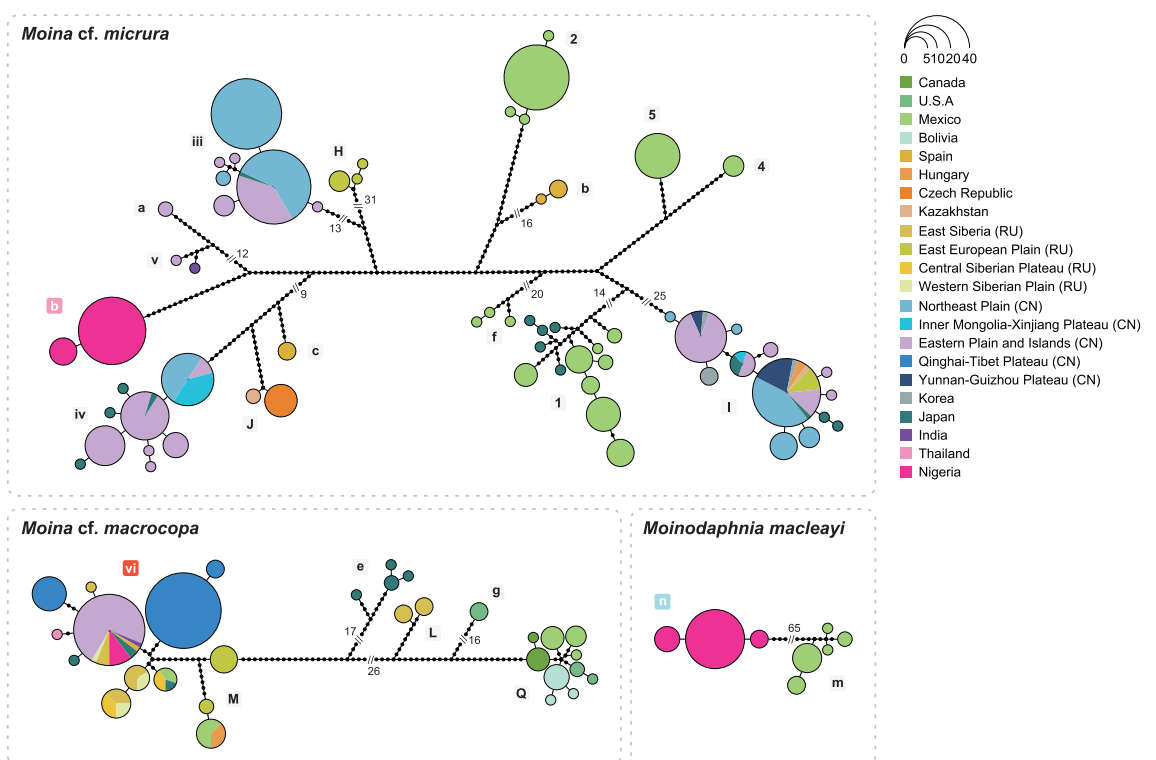

FIGURE 5 Haplotype network of Moinidae lineages within species, based on the mitochondrial cor gene (478 bp). Each circle represents a unique haplotype and its size reflects the number of sequences. Segment sizes within circles indicate the distribution of haplotypes among different regions (color key to regions is on the left side of the figure). The lineage ID s are shown in columns relating to the species-delimitation methods, and those newly detected from Nigeria are indicated in colored squares. The number of marks on connecting lines shows the number of mutations separating haplotypes.

Gabaldon et al., 2016) and cladocerans (e.g., Adamowicz et al., 2009; Forro et al., 2008; Petrusek et al., 2012).

Studies on Moina in Eurasia have generally found several coi lineages representing each morpho-species (Bekker et al., 2016; Ni et al., 2019). In contrast, we detected only one lineage per moinid species from Southeast Nigeria, suggesting a low lineage diversity per species there. It is important to point out, however, that we only sampled a few individuals collected over a short span of time in a small geographical area.

\section{Gene introgression among moinid lineages}

Mito-nuclear discordances, signatures of hybridization and introgression have been frequently reported in animals (reviewed in Toews \& Brelsford, 2012). Examples from Cladocera include species within Daphnia (Thielsch et al., 2017) and Diaphanosoma Fischer, 1850 (Liu et al., 2018). A very recent study has also observed mito-nuclear mismatches in the genus Moina in China: one morphologically $M$. cf. micrura individual possessing $M$. cf. micrura mtDNA had ITS-1 alleles of the $M$. cf. brachiata clade (Ni et al., 2019). In the case of our individuals $\mathrm{N}_{1064-2}$ and $\mathrm{N}_{2} \mathrm{O}_{2-2}$ from Nigeria, the mitochondrial background was of $M$. cf. micrura and the nuclear was of $M$. cf. macrocopa: morphology was also consistent with the latter. This suggests a past hybridization between these two species, followed by introgression into $M$. cf. macrocopa. It is impossible to say how ancient the initial hybridization was: the mitochondrial lineage is distinct from other lineages of $M$. cf. micrura, which could reflect an ancient origin, or could reflect a local Nigerian population of $M$. cf. micrura that has not previously been sampled. We prefer the latter explanation: the same mitochondrial lineage was found in individual $\mathrm{N}_{2} \mathrm{O}_{24}-4$, which we 
believe to be a result of recent hybridization. This individual had two ITs-2 alleles, one typical of $M$. cf. micrura and the other typical of $M$. cf. macrocopa (unfortunately we did not have sufficient DNA to amplify ITS-1 for further confirmation). F1 hybrids (or individuals clonally descended from them) would be expected to have ITs (and other nuclear) alleles typical of both parental species in equal proportions (Dunn et al., 2012; Harrison and Larson, 2014). Back-crossing of the hybrid into only one of the parental species will, over generations, greatly reduce the representation of nuclear genes of the other species (Breeuwer \& Werren, 1995). Thus, we believe individual $\mathrm{N}_{10} \mathrm{O}_{24} 4$ to be a relatively recent hybrid. Our data therefore suggested that gene introgression/hybridization occurs between $M$. cf. micrura and $M$. cf. macrocopa in Southeast Nigeria. Interestingly, we found that these two species could co-exist in the same lakes. Sympatry provides a possibility for interspecific hybridization that is a frequently observed in zooplankton (Smirnov, 1976). Although cyto-nuclear discordance in Moina most likely results from hybridization and subsequent introgression of the mitochondrial genome (Gompert et al., 2008; Linnen \& Farrell, 2007), other explanations are possible. These include incomplete lineage sorting of ancestral polymorphisms (Franco et al., 2015; Mckay \& Zink, 2010), and selection acting on mitochondrial genes (Cheviron \& Brumfield, 2009; Pavlova et al., 2013).

In agreement with a recent study (Ni et al., 2019), our data showed apparent paraphyly in the cor phylogeny of moinid species. This phenomenon could reflect introgression of mitochondrial genomes of one species into the nuclear background of another following hybridization (Funk \& Omland, 2003). Paraphyly in phylogenies has already been detected in other cladocerans, especially in the water-flea genus Daphnia (e.g., Colbourne et al., 1998; Hebert et al., 1989). For example, populations of $D$. pulicaria Forbes, 1893 contain mtDNA genomes derived through introgression with $D$. pulex Leydig, 186o, rendering the former paraphyletic with respect to the latter (Hebert et al., 1989). Another explanation for apparent paraphyly is misidentification of specimens for which sequences have been deposited in GenBank.

\section{Phylogeography of Moinidae}

Our mtDNA-based haplotype network shows that $M$. cf. micrura (type locality Czech Republic) has a global distribution and many lineages. This species is represented in Southeast Nigeria only by one new lineage (including two haplotypes) found nowhere else to date. Previous studies have shown that Moina lineages can be restricted to a certain region (Ni et al., 2019; Smirnov, 1976), which may be a common phenomenon among globally distributed zooplankton taxa (e.g., Andrews et al., 2014; Colbourne et al., 1998; Cornils et al., 2017). However, one haplotype of $M$. cf. macrocopa (type locality of M. macrocopa s.str. is Europe) that we found in Nigeria has also been detected in China (Eastern Plain), India, Japan, Russia (East Siberia and Western Siberian Plain) and Spain. One ITS-1 allele of $M$. cf. macrocopa that we found in Nigeria has also been reported from China. It seems that at least some lineages of this species are very widespread, suggesting relatively recent dispersal. Indeed, it is evident that $M$. cf. macrocopa is a widespread Old-World species, known from across the Palaearctic as well as from Uganda (Montoliu-Elena et al., 2019) and now Nigeria. For such global distribution, birds could be important vectors for the passive dispersal of dormant eggs of freshwater zooplankton (Havel \& Shurin, 2004). The dispersal of $M$. cf. macrocopa could be also due to recent human transport. The potential for humans to unwittingly translocate zooplankton taxa requires further investigation. 
Moinodaphnia macleayi (type locality Australia) is widely distributed in Afrotropical, Australasian, Nearctic, Neotropical, Oriental, and Palaearctic regions (Kotov et al., 2013; Smirnov, 1976). However, the taxonomy of the genus Moinodaphnia is not well developed. Our data shows a new lineage (i.e., " $n$ ") of Moinodaphnia macleayi from Nigeria. This lineage could belong to the "forgotten" taxon Moinodaphnia mocquerysi Richard, 1892, which has been regarded as a junior synonym of $M$. macleayi (Kotov \& Ferrari, 2010). Further studies are called for to put this lineage into an appropriate global phylogeography of the genus Moinodaphnia. Also, further sampling in Nigeria, and West Africa generally, is needed to check for the presence of other species from Moinidae in this region. Several moinids, e.g., M. dumonti Kotov, ElíasGutiérrez \& Granados-Ramírez, 2005, have been described from tropical South America (Kotov et al., 2005). It will be interesting to discover whether some of these also occur in tropical Africa.

In conclusion, we have detected three distinct species of Moinidae within a small geographical area in Southeast Nigeria. Our data revealed several examples of discordance between mtDNA and nuclear ITs phylogenies, indicative of interspecific hybridization and subsequent introgression between Moinidae species. Future studies are called for to investigate other geographical areas, and more habitat types such as puddles, small temporary pools and natural lakes, to ensure the lineage diversity and gene introgression in Moinidae from Africa are better undersood.

\section{Acknowledgments}

The authors declare that they have no competing interests. This research was funded by the National Natural Science Foundation of China (31971396) to MY. We thank Alexey Kotov and one anonymous reviewer for useful comments on the earlier version of this manuscript.

\section{Authors' contributions}

MY designed the study. ZD, JW, EC, OE and OJ carried out the sampling and molecular work, ZD, JW, YN, DB, WH and MY analysed and interpreted genetic data. MY wrote the manuscript with the help of ZD. All authors read and approved the final version.

\section{Competing interests}

The authors declare no conflicts of interest.

\section{Supplementary material}

Supplementary material is available online at: https://doi.org/10.6o84/mg.figshare.14914956

\section{References}

Adamowicz, S. J., A. Petrusek, J. K. Colbourne, P. D. N. Hebert \& Witt, J. D. S. (2009) The scale of divergence: A phylogenetic appraisal of intercontinental allopatric speciation in a passively dispersed freshwater zooplankton genus. Mol. Phylogenet. Evol., 50, 423-436.

Andrews, K. R., E. L. Norton, I. Fernandez-Silva, E. Portner \& Goetze, E. (2014) Multilocus evidence for globally distributed cryptic species and distinct populations across ocean gyres in a mesopelagic copepod. Mol. Ecol., 23, 5462-5479.

Baas-Becking, L. (1934) Geobiologie of inleiding tot de milieukunde. W.P. van Stockum and Zoon, The Hague, The Netherlands. 
Bekker, E. I., D. P. Karabanov, Y. R. Galimov \& Kotov, A. A. (2016) DNA barcoding reveals high cryptic diversity in the North Eurasian Moina species (Crustacea: Cladocera). Plos One, 11.

Bohonak, A. J. \& Jenkins, D. G. (2003) Ecological and evolutionary significance of dispersal by freshwater invertebrates. Ecol Lett, 6, 783-796.

Bouckaert, R., Heled, J., Kuhnert, D., Vaughan, T., Wu, C. H., Xie, D., Suchard, M. A., A. Rambaut \& Drummond, A. J. (2014) BEAST 2: a software platform for Bayesian evolutionary analysis. Plos Comput. Biol., 10.

Breeuwer, J. A. J. \& Werren, J. H. (1995) Hybrid breakdown between two haplodiploid species - the role of nuclear and cytoplasmic genes. Evolution, 49, 705-717.

Cheviron, Z. A. \& Brumfield, R. T. (2009) Migrationselection balance and local adaptation of mitochondrial haplotypes in rufous-collared sparrows (Zonotrichia Capensis) along an elevational gradient. Evolution, 63, 1593-1605.

Colbourne, J. K., T. J. Crease, L. J. Weider, P. D. N. Hebert, F. Dufresne \& Hobaek, A. (1998) Phylogenetics and evolution of a circumarctic species complex (Cladocera: Daphnia pulex). Biol. J. Linn. Soc., 65, 347-365.

Cornils, A., B. Wend-Heckmann \& Held, C. (2017) Global phylogeography of Oithona similis s.l. (Crustacea, Copepoda, Oithonidae) - A cosmopolitan plankton species or a complex of cryptic lineages? Mol. Phylogenet. Evol., 107, 473-485.

Darriba, D., G. L. Taboada, R. Doallo \& Posada, D. (2012) jModelTest 2: more models, new heuristics and parallel computing. Nat. Methods, 9, 772-772.

Degnan, J. \& Rosenberg, N. (2006) Discordance of species trees with their most likely gene trees. Plos Genet., 2.

Delmotte, F., Sabater-Munoz, B., Prunier-Leterme, N., Latorre, A., Sunnucks, P., C. Rispe \& Simon, J. C. (2003) Phylogenetic evidence for hybrid origins of asexual lineages in an aphid species. Evolution, 57, 1291-1303.
Dumont, H. \& Negrea, S. (2002) Introduction to the class Branchiopoda. In: Dumont, H. J., Guides to the identification of the microinvertebrates of the continental waters of the world 19. Backhuys Publishers, Leiden, 398 pp.

Dunn, B., C. Richter, D. J. Kvitek, T. Pugh \& Sherlock, G. (2012) Analysis of the Saccharomyces cerevisiae pan-genome reveals a pool of copy number variants distributed in diverse yeast strains from differing industrial environments. Genome Res., 22, 908-924.

Edgar, R. C. (2004) MUSCLE: multiple sequence alignment with high accuracy and high throughput. Nucleic Acids Res., 32, 1792-1797.

Egborge, A., C. Onwudinjo \& Chigbu, P. (1994) Cladocera of coastal rivers of western Nigeria. Hydrobiologia, 272, 39-46.

Elias-Gutierrez, M., P. J. Juracka, L. MontoliuElena, M. R. Miracle, A. Petrusek \& Korinek, V. (2019) Who is Moina micrura? Redescription of one of the most confusing cladocerans from terra typica, based on integrative taxonomy. Limnetica, 38, 227-252.

Etile, R. N., T. A. Bedia, G. K. Blahoua, G. G. Bi, P. E. Kouamelan \& N'Douba, V. 2020. Checklist and distribution of freshwater Cladocera (Crustacea: Branchiopoda) in Cote d'Ivoire (West Africa).Zool. Stud., 59 .

Ezard, T., T. Fujisawa \& Barraclough, T. (2009) Splits: SPecies' LImits by threshold statistics $\mathrm{R}$ package.

Folmer, O., M. Black, W. Hoeh, R. Lutz \& Vrijenhoek, R. (1994) DNA primers for amplification of mitochondrial cytochrome c oxidase subunit I from diverse metazoan invertebrates. Mol. Mar. Biol. Biotechnol., 3, 294-299.

Fontaneto, D., M. Kaya, E. Herniou \& Barraclough, T. (2009) Extreme levels of hidden diversity in microscopic animals (Rotifera) revealed by DNA taxonomy. Mol. Phylogenet. Evol., 53, 182-189.

Forro, L., N. M. Korovchinsky, A. A. Kotov \& Petrusek, A. (2008) Global diversity of 
cladocerans (Cladocera; Crustacea) in freshwater. Hydrobiologia, 595, 177-184.

Franco, F. F., T. C. Lavagnini, F. M. Sene \& Manfrin, M. H. (2015) Mito-nuclear discordance with evidence of shared ancestral polymorphism and selection in cactophilic species of Drosophila. Biol. J. Linn. Soc., 116, 197-210.

Frey, D. G. (1987) The Taxonomy and biogeography of the Cladocera. Hydrobiologia, 145, 5-17.

Funk, D. J. \& Omland, K. E. (2003) Species-level paraphyly and polyphyly: Frequency, causes, and consequences, with insights from animal mitochondrial DNA. Annu. Rev. Ecol. Evol. S. 34, 397-423.

Gabaldon, C., D. Fontaneto, M. Carmona, J. Montero-Pau \& Serra, M. (2016) Ecological differentiation in cryptic rotifer species: what we can learn from the Brachionus plicatilis complex. Hydrobiologia, 796, 7-18.

Ghaouaci, S., M. Amarouayache, A. Y. Sinev, N. M. Korovchinsky \& Kotov, A. A. (2018) An annotated checklist of the Algerian Cladocera (Crustacea: Branchiopoda). Zootaxa, 4388, 592-6oo.

Gompert, Z., M. L. Forister, J. A. Fordyce \& Nice, C. C. (2008) Widespread mito-nuclear discordance with evidence for introgressive hybridization and selective sweeps in Lycaeides. Mol. Ecol., 17 , 5231-5244.

Goulden, C. (1968) The systematics and evolution of the Moinidae. Trans. Am. Philos. Soc., 58, 1-101.

Harrison, R. G. \& Larson, E. L. (2014) Hybridization, introgression, and the nature of species boundaries. J. Hered., 105, 795-8o9.

Havel, J. E. \& Shurin, J. B. (2004) Mechanisms, effects, and scales of dispersal in freshwater zooplankton. Limnol. Oceanogr., 49, 1229-1238.

Hebert, P. D. N. (1985) Interspecific hybridization between cyclic parthenogens. Evolution, 39, 216-22o.

Hebert, P. D. N., M. J. Beaton, S. S. Schwartz \& Stanton, D. J. (1989) Polyphyletic origins of asexuality in Daphnia pulex. I. Breeding-system variation and levels of clonal diversity. Evolution, 43, 1004-1015.

Huelsenbeck, J. P. \& Ronquist, F. (2001) MRBAYES: Bayesian inference of phylogenetic trees. Bioinformatics, 17, 754-755.

Jeje, C. (1989) The cladoceran fauna of Nigeria: A checklist, review of literature and distribution. Rev. D'Hydrobiol. Trop., 22, 1-12.

Kotov, A. A., M. Elias-Gutierrez \& GranadosRamirez, J. G. (2005) Moina dumonti sp nov (Cladocera, Anomopoda, Moinidae) from southern Mexico and Cuba, with comments on moinid limbs. Crustaceana, 78, 41-57.

Kotov, A. A. \& Ferrari, F. D. (2010) The taxonomic research of Jules Richard on Cladocera (Crustacea: Branchiopoda) and his collection at the National Museum of Natural History, USA. Zootaxa, 2551, 37-64.

Kotov, A. A., L. Forro, N. M. Korovchinsky \& Petrusek, A. (2013) World checklist of freshwater Cladocera species. http:/fada.biodiversity.be/ group/show/17. Accessed on: 10 October 2020.

Kumar, S., G. Stecher, M. Li, C. Knyaz \& Tamura, K. (2018) MEgA X: Molecular Evolutionary Genetics Analysis across computing platforms. Mol. Biol. Evol., 35, 1547-1549.

Lamoot, E. \& Dumont, H. (1974) Moina reticulata (Daday, 1905) (Cladocera, Moinidae) found in the Ivory Coast, West Africa. Crustaceana, 26, 29-32.

Linder, R. \& Rieseberg, L. H. (2004) Reconstructing patterns of reticulate evolution in plants. Am.J. Bot., 91, 1700-1708.

Linnen, C. R. \& Farrell, B. D. (2007) Mitonuclear discordance is caused by rampant mitochondrial introgression in Neodiprion (Hymenoptera: Diprionidae) sawflies. Evolution, 61, 1417-1438.

Liu, P., Xu, L., Xu, S. L., Martinez, A., Chen, H., Cheng, D., Dumont, H. J., B. P. Han \& Fontaneto, D. (2018) Species and hybrids in the genus Diaphanosoma Fischer, $185^{\circ}$ (Crustacea: Branchiopoda: Cladocera). Mol. Phylogenet. Evol., 118: 369-378. 
Ma, X., W. Hu, P. Smilauer, M. Yin \& Wolinska, J. (2019) Daphnia galeata and D. dentifera are geographically and ecologically separated whereas their hybrids occur in intermediate habitats: survey of 44 Chinese lakes. Mol. Ecol., 28, 785-802.

Makino, W., R. J. Machida, J. Okitsu \& Usio, N. (2020) Underestimated species diversity and hidden habitat preference in Moina (Crustacea, Cladocera) revealed by integrative taxonomy. Hydrobiologia, 847, 857-878.

Mallet, J. (2005) Hybridization as an invasion of the genome. Trends Ecol. Evol., 20, 229-237.

Marrone, F., M. Korn, F. Stoch, L. NaselliFlores \& Turki, S. (2016) Updated checklist and distribution of large branchiopods (Branchiopoda: Anostraca, Notostraca, Spinicaudata) in Tunisia. Biogeographia, 31.

Marrone, F., S. Lo Brutto, A. K. Hundsdoerfer \& Arculeo, M. (2013) Overlooked cryptic endemism in copepods: Systematics and natural history of the calanoid subgenus Occidodiaptomus Borutzky 1991 (Copepoda, Calanoida, Diaptomidae).Mol. Phylogenet. Evol., 66, 19o-202.

Mckay, B. D. \& Zink, R. M. (2010) The causes of mitochondrial DNA gene tree paraphyly in birds. Mol. Phylogenet. Evol., 54, 647-65o.

Mirabdullayev, I. M. (1998) Moina mukhamedievi n. sp. (Crustacea, Cladocera) from ricefields of Uzbekistan (central Asia). Hydrobiologia, 385, 11-16.

Montoliu-Elena, L., M. Elias-Gutierrez \& SilvaBriano, M. (2019) Moina macrocopa (Straus, 1820): a species complex of a common Cladocera, highlighted by morphology and D NA barcodes. Limnologica, 38, 253-277.

Myers, N., R. A. Mittermeier, C. G. Mittermeier, G. A. B. da Fonseca \& Kent, J. (200o) Biodiversity hotspots for conservation priorities. Nature, $403,853-858$.

Nedli, J., L. De Meester, A. Major, K. Schwenk, I. Szivak \& Forro, L. (2014) Salinity and depth as structuring factors of cryptic divergence in
Moina brachiata (Crustacea: Cladocera). Fund. Appl. Limnol., 184, 69-85.

Neretina, A. \& Kirdyasheva, A. (2019) A redescription of Moina australiensis Sars, 1896 (Cladocera: Moinidae) with short notes on Australian moinids. Zootaxa, 4577, 161-179.

Neretina, A. N., D. P. Karabanov, V. Sacherova \& Kotov, A. A. (2021) Unexpected mitochondrial lineage diversity within the genus Alonella Sars, 1862 (Crustacea: Cladocera) across the Northern Hemisphere. Peerj, 9 .

Ni, Y. J., X. L. Ma, W. Hu, D. Blair \& Yin, M. (2019) New lineages and old species: Lineage diversity and regional distribution of Moina (Crustacea: Cladocera) in China. Mol. Phylogenet. Evol., 134, $87-98$.

Nichols, R. (2001) Gene trees and species trees are not the same. Trends Ecol. Evol., 16, 358-364.

Ovie, S. \& Adeniji, H. (1994) Zooplankton and environmental characteristics of Shiroro Lake at the extremes of its hydrological cycle. Hydrobiologia, 286, 175-182.

Padhye, S. M. \& Dumont, H.J. (2014) Moina hemanti sp nov., a new species of the genus Moina s.l. (Branchiopoda: Anomopoda) from Pune, India. Zootaxa, 386o, 561-570.

Pavlova, A., Amos, J. N., Joseph, L., Loynes, K., Austin, J.J., Keogh, J. S., Stone, G. N., J. A. Nicholls \& Sunnucks, P. (2013) Perched at the mitonuclear crossroads: divergent mitochondrial lineages correlate with environment in the face of ongoing nuclear gene flow in an Australian bird. Evolution, 67, 3412-3428.

Penner, J., M. Wegmann, A. Hillers, M. Schmidt \& Redel, M. (2013) A hotspot revisited - a biogeographical analysis of West African amphibians. Divers. Distrib., 17, 1077-1088.

Penton, E. H., P. D. N. Hebert \& Crease, T. J. (2004) Mitochondrial DNA variation in North American populations of Daphnia obtusa: continentalism or cryptic endemism? Mol. Ecol., 13, 97-107.

Petrusek, A., M. Cerny \& Audenaert, E. (2004) Large intercontinental differentiation of Moina 
micrura (Crustacea: Anomopoda): one less cosmopolitan cladoceran? Hydrobiologia, 526, 73-81.

Petrusek, A., A. Thielsch \& Schwenk, K. (2012) Mitochondrial sequence variation suggests extensive cryptic diversity within the Western Palearctic Daphnia longispina complex. Limnol. Oceanogr., 57, 1838-1845.

Pons, J., Barraclough, T. G., Gomez-Zurita, J., Cardoso, A., Duran, D. P., Hazell, S., Kamoun, S., W. D. Sumlin \& Vogler, A. P. (2006) Sequencebased species delimitation for the DNA taxonomy of undescribed insects. Syst. Biol., 55, 595-6o9.

R Development Core Team. (2013) R: a language and environment for statistical computing. $\mathrm{R}$ foundation for statistical computing, Vienna, Austria.

Rambaut, A., A. J. Drummond, D. Xie, G. Baele \& Suchard, M. A. (2018) Posterior summarisation in Bayesian phylogenetics using Tracer 1.7. Syst. Biol., 67, 901-904.

Rosenberg, N. (2013) Discordance of species trees with their most likely gene trees: a unifying principle. Mol. Biol. Evol., 30, 2709-2713.

Rozas, J., Ferrer-Mata, A., Sanchez-DelBarrio, J., Guirao-Rico, S., Librado, P., S. Ramos-Onsins \& Sanchez-Gracia, A. (2017) DnaSP 6: DNA sequence polymorphism analysis of large data sets. Mol. Biol. Evol., 34, 3299-3302.

Salzburger, W., G. B. Ewing \& von Haeseler A. (2011) The performance of phylogenetic algorithms in estimating haplotype genealogies with migration. Mol. Ecol., 20, 1952-1963.

Schwenk, K., Sand, A., Boersma, M., Brehm, M., Mader, E., D. Offerhaus \& Spaak, P. (1998) Genetic markers, genealogies and biogeographic patterns in the Cladocera. Aquat. Ecol., 32, 37-51.

Smirnov, N. (1976) Macrothricidae and Moinidae of the World fauna. Fauna sssR, novaya seriya. Rakoobraznye, 1, 1-237.
Smirnov, N. N. (2008) Check-list of the SouthAfrican Cladocera (Crustacea: Branchiopoda). Zootaxa, 1788, 47-56.

Taylor, D. J., H. L. Sprenger \& Ishida, S. (2005) Geographic and phylogenetic evidence for dispersed nuclear introgression in a daphniid with sexual propagules. Mol. Ecol., 14, 525-537.

Thielsch, A., A. Knell, A. Mohammadyari, A. Petrusek \& Schwenk, K. (2017) Divergent clades or cryptic species? Mito-nuclear discordance in a Daphnia species complex. BMC Evol. Biol., 17.

Thompson, J. D., D. G. Higgins \& Gibson, T. J. (1994) Clustal W: improving the sensitivity of progressive multiple sequence alignment through sequence weighting, position-specific gap penalties and weight matrix choice. Nucleic Acids Res., 22, 4673-468o.

Toews, D. P. L. \& Brelsford, A. (2012) The biogeography of mitochondrial and nuclear discordance in animals. Mol. Ecol., 21, 3907-3930.

Wang, J., Y. Ni, W. Hu \& Yin, M. (2021) Lineage diversity and gene introgression in freshwater cladoceran crustaceans of the Chydorus sphaericus species complex. Limnol. Oceanogr., 66, 95-107.

Xia, X. H. (2013) DAMBE5: A comprehensive software package for data analysis in molecular biology and evolution. Mol. Biol. Evol., 30, 1720-1728.

Xia, X. H., Z. Xie, M. Salemi, L. Chen \& Wang, Y. (2003) An index of substitution saturation and its application. Mol. Phylogenet. Evol., 26, 1-7.

Xu, S., D. J. Innes, M. Lynch \& Cristescu, M. E. (2013) The role of hybridization in the origin and spread of asexuality in Daphnia. Mol. Ecol., 22, 4549-4561.

Zhang, J. J., P. Kapli, P. Pavlidis \& Stamatakis, A. (2013) A general species delimitation method with applications to phylogenetic placements. Bioinformatics, 29, 2869-2876.

RECEIVED: 24 APRIL 2021 | REVISED AND

ACCEPTED: 1 JULY 2021

EDITOR: D. COPILAS-CIOCIANU 